\title{
A COMPARISON OF THE PH OF ARTERIAL BLOOD WITH ARTERIALISED BLOOD FROM THE EAR-LOBE WITH ASTRUP'S MICRO GLASSELECTRODE
}

\author{
A. H. J. MAAS AND A. N. P. VAN HEIJST* \\ Departments of Cardiology** and Lung Diseases***, State University Hospital, \\ Utrecht (The Netherlands)
}

(Received February 3rd, 1960)

\section{INTRODUCTION}

The value of the pH of blood is one of the measurable factors in the investigation of disturbances of the acid-base balance. The usual types of electrode circuits need I $-3 \mathrm{ml}$ of blood. Usually arterial blood is used and is obtained by puncture of an artery, e.g. the arteria brachialis, but this procedure is not without danger for the patient; it takes about 15 min and has to be performed by a physician. A rapid and simple method of sampling, which can be used by technicians is therefore desirable for clinical use. If a method for the determination of the pH of small samples of blood were available, a puncture of a fingertip or earlobe would be suitable.

SANZ ${ }^{1}$ constructed a micro capillary glass electrode with a capacity of $10 \mu \mathrm{l}$, with which the $\mathrm{pH}$ of blood could be determined in I min; he used fingertip blood. The fingertip was arterialised by holding the hand in warm water for $20 \mathrm{~min}$. The electrode (Metrohm) has the drawback of instability by "creeping" of the potassium chloride and often the capillary slowly empties itself.

AstruP $^{2}$ has built in co-operation with Radiometer, Copenhagen, a handymicro-electrode which is very stable. The capillary was fitted in a horizontal position and fused into the surrounding glass tube whereby damage and leakage were practically excluded. He took blood from the unarterialised ear-lobe and assumed that its $\mathrm{pH}$ equalled that of the arterialised blood. We have tested this electrode and compared the value of the pH of arterial blood with the pH of the blood from an ear-lobe arterialised by local application of trafuril paste (Ciba).

\section{APPARATUS}

A pH-meter (type $\mathrm{PH} 22$, with external meter pH 6-8, Radiometer, Copenhagen) served as the measuring instrument. The electrode circuit consisted of a Radiometer micro glass electrode (type GS278), a calomel electrode (type Kroo) and a U-tube filled with saturated $\mathrm{KCl}$-solution. We did not use the original calomel electrode which is surrounded by a water-jacket and thermostat set a $37.5^{\circ}$. As some hours are needed before the potential is constant and thermostatting the electrode constantly at the right temperature has objections, we replaced this electrode in our set-up by an unwarmed one of the type $\mathrm{K}$ Ioo. A suction pump was used for sucking the fluids into the glass clectrode. Discarded fluids were drawn into a flask between clectrode and pump. By means of a circulation pump thermostat (Haake, Berlin), the glass electrode and a lucite tray with buffer and rinsing spolutions (Fig. I) were kept at $37.5^{\circ}$.

* With technical assistance of Miss M. Kronenburg.

** Head of Department: Prof. R. L. J. VAN Ruyven.

*** Head of Department: Prof. H. DeEnstra. 


\section{(I) Blood sampling}

PROCEDURE

(a) Blood sampling from the arteria brachialis. The skin over the arteria brachialis was cleaned with alcohol and iodine tincture; $4 \mathrm{ml}$ of $2 \%$ astracaine solution was injected subcutaneously. Then a Cournand needle was introduced into the artery; $5 \mathrm{ml}$ of blood was drawn into a 5 -ml syringe(Luer-Lock) of which the dead space was filled with a heparine-sodium fluoride solution ( $0.4 \mathrm{mg}$ heparine/ml; $2 \mathrm{mg} \mathrm{NaF} / \mathrm{ml}$ ). Afterwards a drop of mercury was sucked in to mix the blood with the heparine solution.

(b) Blood sampling from the earlobe. We used a glass capillary (12-cm length) with an iron nail in it. The capillary was filled with the heparine-sodium fluoride solution and then dried (Radiometer). Local hyperaemia was achieved by rubbing the earlobe with trafuril paste. After 5 min the earlobe was cleaned with alcohol and pricked with a snapper. The first drop of blood was mopped off; the capillary was

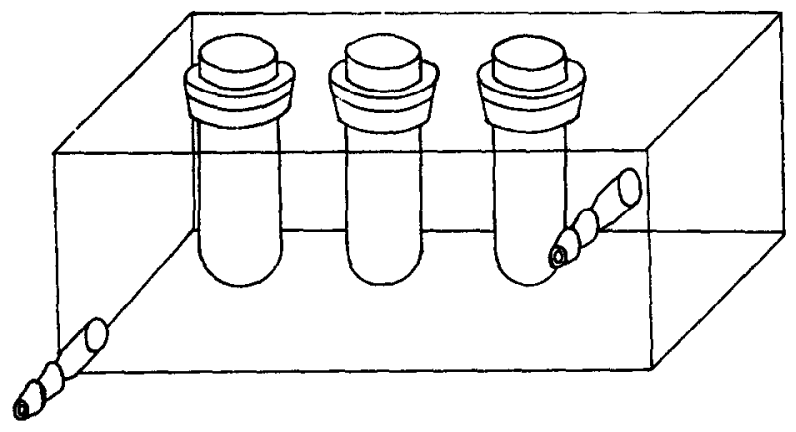

Fig. I. Lucite tray with aqua dist., saline solution and buffer.

filled with the next big drop and both ends were then sealed with plastic putty. The nail was moved to and fro with a magnet to mix the heparine-sodium fluoride mixture with the blood.

\section{(2) Preservation of the blood}

When the glass capillaries were kept at $20^{\circ}$ a decrease of $0.0003 \mathrm{pH}$ unit $/ \mathrm{min}$ was found. The blood of the capillaries slored in the icebux showed a decrease of $0.0001 \mathrm{pH}$ unit/min at $5^{\circ}$. Thus it was necessary to determine the $\mathrm{pH}$ of the blood within Io min after drawing the sample, unless the capillaries were stored at $5^{\circ}$.

\section{(3) Calibrating and checking the measuring circuit}

For checking the electrode circuit and pH-meter we used two phosphate buffers of $\mathrm{pH}=6.835$ at $37.5^{\circ}\left(3.4023 \mathrm{~g} \mathrm{KH}_{2} \mathrm{PO}_{4}\right.$ and $4.4503 \mathrm{~g} \mathrm{Na}_{2} \mathrm{HPO}_{4} \cdot 2 \mathrm{H}_{2} \mathrm{O}$ per litre) and $\mathrm{pH}=7.375$ et $37.5^{\circ}\left(9.4938 \mathrm{~g} \mathrm{Na}_{2} \mathrm{HPO}_{4} \cdot 2 \mathrm{H}_{2} \mathrm{O}\right.$ and I.8I47 $\mathrm{g} \mathrm{KH}_{2} \mathrm{PO}_{4}$ per litre, "Merck" chemicals).

The asymmetry potential of the electrode was adjusted with buffer $\mathrm{pH} 7 \cdot 375$. The stability of the electrodes was tested by repeating ro times in succession the measurement with phosphate buffer 7.375; we found deviations of $\pm 0.002 \mathrm{pH}$.

When the clectrode circuit was thermostatted for more than half an hour, it appeared that the asymmetry potential was constant and there was no drift during the first two hours.

(4) $p \mathrm{H}-$ measurement of blood

At first the electrode was adjusted with phosphate buffer 7.375 and thereupon 
the electrode was filled with isotonic salt solution. Before sucking in, the blood was mixed with the magnet and nail; then both ends of the capillary were cut off and the electrode was filled with blood by suction. When blood was used from a syringe, first the blood was mixed with a drop of mercury and then the polyethylene tube was brought into the syringe and the electrode filled. After the plastic tube of the electrode

TABLE I

\begin{tabular}{|c|c|c|c|}
\hline No. & $\begin{array}{l}p \mathrm{H} \text {-value of } \\
\text { blood from } \\
\text { the artery }\end{array}$ & $\begin{array}{l}p \mathrm{H}-\mathrm{v} a \text { alue of } \\
\text { blood from } \\
\text { the earlobe }\end{array}$ & $\begin{array}{c}\text { Difference } \\
\text { earlcbe-artery }\end{array}$ \\
\hline I & $7 \cdot 3^{80}$ & $7 \cdot 385$ & +0.005 \\
\hline 2 & $7 \cdot 399$ & $7 \cdot 39^{\circ}$ & -0.009 \\
\hline 3 & 7.415 & $7 \cdot 416$ & +0.001 \\
\hline 4 & $7 \cdot 353$ & $7 \cdot 35^{\circ}$ & -0.003 \\
\hline 5 & $7 \cdot 393$ & 7.407 & +0.014 \\
\hline 6 & $7 \cdot 413$ & $7 \cdot 422$ & +0.008 \\
\hline 7 & 7.410 & $7 \cdot 420$ & +0.010 \\
\hline 8 & 7.415 & 7.410 & -0.005 \\
\hline 9 & 7.428 & 7.420 & -0.008 \\
\hline Io & $7 \cdot 34^{\circ}$ & $7 \cdot 34^{8}$ & +0.008 \\
\hline II & $7 \cdot 4^{23}$ & $7 \cdot 412$ & -0.009 \\
\hline I 2 & 7.370 & 7.375 & +0.005 \\
\hline I 3 & 7.4 I5 & 7.410 & -0.005 \\
\hline $\mathrm{I}_{4}$ & 7.397 & 7.405 & +0.008 \\
\hline I 5 & $7 \cdot 365$ & $7 \cdot 37^{\circ}$ & +0.005 \\
\hline I6 & 7.495 & 7.510 & +0.015 \\
\hline I 7 & $7 \cdot 420$ & $7.43^{\circ}$ & +o.010 \\
\hline I 8 & 7.464 & 7.468 & +0.004 \\
\hline I9 & $7 \cdot 498$ & $7 \cdot 495$ & -0.003 \\
\hline 20 & $7 \cdot 433$ & $7 \cdot 428$ & -0.005 \\
\hline $2 I$ & $7 \cdot 312$ & 7.308 & -0.004 \\
\hline 22 & 7.335 & $7 \cdot 343$ & +0.008 \\
\hline
\end{tabular}

had been placed in the $\mathrm{KCl}$-solution the value of the $\mathrm{pH}$ was read. Thereafter the electrode was filled with isotonic salt solution and distilled water and checked again with buffer 7.375 .

\section{RESULTS}

Blood was taken from the arteria brachialis and the ear-lobe of 22 patients. Special attention was paid to the steady state of the patient because changes in the respiration cause changes in the pH values of the blood ${ }^{3}$. In Table I the values for blood from the artery and the earlobe are summarized. The difference blood earlobe-blood artery is $+0.0023 \pm 0.0075$.

\section{SUMMARY}

The pH of arterial blood and the blood from an arterialised ear-lobe are compared. The small difference $( \pm 0.002 \mathrm{pH})$ is not important in studying the changes of the acid-base balance. It is concluded that blood obtained by puncture of the arterialised earlobe is a good substitute for blood obtained by arterial puncture.

\section{REFERENCES}

1 M. C. Sanz, Clin. Chem., 3 (1957) 407.

2 P. Astrup, Ciba Foundation Research Forum, (1958).

${ }^{3}$ C. E. King And E. W. Benz, Science, 92 (1940) 409. 